\title{
A1166C variant of angiotensin II type 1 receptor gene is associated with severe hypertension in pregnancy independently of T235 variant of angiotensinogen gene
}

Received: 7 October 2003 / Accepted: 9 January 2004/Published online: 23 March 2004

(C) The Japan Society of Human Genetics and Springer-Verlag 2004

\begin{abstract}
Hypertension in pregnancy (HP) is a multifactorial disease manifested due to a complex combination of environmental factors and several predisposing genes including factors in the renin angiotensin system. The aim of this study was to assess the association between the A1166C variant of the angiotensin II type 1 receptor (AT1) gene and severe HP. We carried out association studies and multivariate analyses including other candidate causal factors of HP such as the M235T variant of the angiotensinogen (AGT) gene, prepregnancy body mass index (BMI), and family history of hypertension in Japanese subjects. One hundred and fourteen patients with severe HP and 291 normal pregnancy controls were genotyped. Among primiparous subjects, the frequency of "AC $+\mathrm{CC}$ genotype of AT1" was significantly higher in severe HP than in the controls. A multivariate analysis with "AC $+\mathrm{CC}$ genotype of AT1" and "TT genotype of AGT" revealed that these were independently associated with primiparous severe HP. However, when "family history of hypertension" and "prepregnancy BMI $\geq 25$ " were added as factors examined in the multivariate analysis, only "TT
\end{abstract}

G. Kobashi $(\bowtie) \cdot$ K. Ohta

Division of Preventive Medicine, Hokkaido University Graduate

School of Medicine, N15 W7, Sapporo 060-8638, Japan

E-mail: genkoba@med.hokudai.ac.jp

Tel.: + 81-11-7065079

Fax: + 81-11-7067374

A. Hata

Department of Public Health,

Chiba University Graduate School of Medicine, Chiba, Japan

H. Yamada E. H. Kato · H. Minakami

Department of Obstetrics and Gynecology,

Hokkaido University Graduate School of Medicine,

Sapporo, Japan

S. Fujimoto

Tenshi Hospital, Sapporo, Japan

K. Kondo

The University of the Air, Chiba, Japan genotype of AGT" and "family history of hypertension" were found to be independent potent factors. The present results suggest that the $\mathrm{C} 1166$ allele of the AT1 gene may be concerned with the predisposition to essential hypertension independently of the T235 allele of the AGT gene.

Keywords Preeclampsia Polymorphism - Multivariate analysis $\cdot$ Body mass index $\cdot$ Family history

\section{Introduction}

Hypertension in pregnancy (HP), including preeclampsia (PE), a proteinuric and/or edematous type of $\mathrm{HP}$, is a major contributor to maternal, fetal, and neonatal morbidity and mortality. HP occurs in about $5 \%$ of pregnancies and is considered to be a multifactorial disease manifested due to a complex combination of environmental factors and several predisposing genes whose products likely interact with each other.

Genes coding for components of the renin angiotensin system involved in blood pressure regulation and vascular smooth muscle cell proliferation are considered to be candidate genes for risk factors for HP as well as essential hypertension. A molecular variant of the angiotensinogen (AGT) gene encoding threonine (T235) instead of methionine (M235) at residue 235 in exon 2 (Jeunemaitre et al. 1992) was shown to be associated with essential hypertension, and this association has been confirmed by some other investigators (Hata et al. 1994; Caulfield et al. 1994). An association with this allele was also demonstrated for primigravid PE in Caucasians (Ward et al. 1993) and HP in Japanese (Kobashi et al. 1999). A promoter mutation of $\mathrm{G}(-6) \mathrm{A}$ is present in $99 \%$ of women with the M235T mutation, and in vitro studies have suggested that the $A(-6)$ may cause elevated AGT expression in vivo (Inoue et al. 1997). Recently, it was reported that T235 might be 
concerned with abnormal pregnancy-induced spiral artery remodeling occurring early in pregnancy, which might lead to reduced uteroplacental blood flow and initiate the cascade of events leading to PE (Morgan et al. 1999).

On the other hand, in 1994, a polymorphism of the angiotensin II type 1 receptor (AT1) gene, namely an adenine/cytosine $(\mathrm{A} / \mathrm{C})$ base substitution at position 1166 located in the $3^{\prime}$ untranslated region, was identified and an increased prevalence of the $\mathrm{C}$ allele in hypertensive disorders was found (Bonnardeaux et al. 1994). This association has been confirmed by some investigators (Szombathy et al. 1998; Jiang et al. 2001) but not by others (Schmidt et al. 1997; Takami et al. 1998). More recent studies further demonstrated associations between the C1166 allele of the AT1 gene and HP in Caucasian (Nalogowska-Glosnicka et al. 2000) and Polish (Seremak-Mrozikiewicz et al. 2000) subjects. However, the C1166 allele of the AT1 gene has not yet been confirmed to be an independent variant when other possible risk factors are included in analyses.

In this study, we investigated the genotype of the AT1 gene in patients with HP and normal pregnant women and detected a significant association of the C1166 variant of the AT1 gene with HP. Further, we carried out a multivariate analysis of the AT1 and AGT genotypes in primiparous subjects and found that these were independently associated with HP, suggesting that the C1166 variant of the AT1 gene may be an additional risk factor for HP.

\section{Materials and methods}

\section{Subjects}

Japanese patients with severe HP and controls were recruited from women who delivered singletons at Hokkaido University Hospital and its affiliated hospitals. Women with preexisting hypertension were excluded to make the present cases the pure type of HP. Women with renal disease, diabetes mellitus, amniotic volume abnormalities, or fetal anomalies were also excluded. Severe HP was diagnosed according to the criteria of the National High Blood Pressure Education Program Working Group (1990). The criteria for severe HP were as follows: (1) a blood pressure reading of $160 / 110 \mathrm{mmHg}$ or more after the 20th gestational week, (2) proteinuria was defined as the excretion of $30 \mathrm{mg} / \mathrm{dl}(1+$ on dipstick $)$ or greater, (3) women with blood pressure of more than $140 / 90 \mathrm{mmHg}$ or proteinuria prior to the 20th gestational week or 4 weeks after delivery were excluded from the HP subjects because they may have had latent hypertensive or renal diseases. Finally, 114 patients with severe HP agreed to participate in this study between 1993 and 1996, and 291 controls were randomly selected from normal pregnant women who also agreed to participate in the study between April 1993 and March 1994. Informed consent for the study was obtained from every subject following guidelines for informed consent in epidemiological studies in Japan (Tamakoshi et al. 2000), and the present study was approved by the institutional review board of Hokkaido University School of Medicine.

Clinical characteristics and pregnancy outcomes of cases of severe HP and controls are shown in Table 1. Prepregnancy body mass index (BMI) and the rate of positive family history of hypertension were significantly higher in the women with severe HP than in the controls, while no significant differences in the rate of primiparas or the maternal age were detected between the two groups. The gestational weeks at delivery were higher and birth weight significantly lower in the severe HP group than in the controls. About $30 \%$ of severe HP cases were complicated with intrauterine fetal growth restriction.

\section{Genotyping}

Genomic DNA was extracted from peripheral leukocytes and the genotyping with respect to the A1166C variant of the AT1 gene was performed by using allelespecific oligonucleotide hybridization of PCR-amplified products as previously described (Bonnardeaux et al. 1994). The occurrence of T235 homozygotes (TT) of the AGT gene was also examined by using $\mathrm{T}$ th111I digestion of PCR-amplified products as previously described (Russ et al. 1993).

\section{Statistical analysis}

Statistical analyses were performed to compare the number of C1166 alleles with that of A1166 alleles for the AT1 gene and the number of C1166 homozygous (CC) plus heterozygous (AC) women with that of A1166 homozygous (AA) women. The differences were analyzed statistically by the chi-square test $(\mathrm{df}=1)$. Yates' correction for continuity was used when an observed number was $\leq 5$.

In the multivariate analysis, a stepwise method was applied to select significant $(p<0.05)$ factors among four factors existing before pregnancy that were significantly associated with HP in univariate analyses, i.e., "family history of hypertension," "prepregnancy high body mass index (BMI $\geq 25)$," "T235 homozygous

Table 1 Clinical characteristics and pregnancy outcomes of women with severe hypertension in pregnancy and normal controls

\begin{tabular}{llll}
\hline & Parity & Severe hypertension in pregnancy $(n=114)$ & Controls $(n=291)$ \\
\hline Percentage (number) of primiparas & & $64.0(73 / 114)$ & $56.7(165 / 291)$ \\
Maternal age (years) (mean \pm SE) & & $29.7 \pm 0.5$ & $29.2 \pm 0.3$ \\
& Primipara & $27.7 \pm 0.5$ & $27.3 \pm 0.3$ \\
Family history of hypertension (\%) & $30.8^{* *}$ & 13.1 \\
& Primipara & $31.5^{* *}$ & 15.2 \\
Prepregnancy body mass index (mean \pm SE) & & $22.5 \pm 0.4^{*}$ & $21.1 \pm 0.2$ \\
Gestational weeks at delivery (mean \pm SE) & Primipara & $21.7 \pm 0.4$ & $20.7 \pm 0.2$ \\
& & $36.6 \pm 0.3^{* *}$ & $39.1 \pm 0.1$ \\
Birth weight of neonates (g) (mean \pm SE) & Primipara & $37.0 \pm 0.3^{* *}$ & $39.2 \pm 0.1$ \\
Percentage of intrauterine growth restriction $(\%)$ & Primipara & $2,444 \pm 80^{* *}$ & $3,160 \pm 21$ \\
& & 31.6 & $3,122 \pm 27$ \\
& Primipara & 37.0 & 0 \\
\hline
\end{tabular}

${ }^{*} p<0.01,{ }^{* *} p<0.001$ versus controls 
(TT) genotype of AGT gene," and "AC + CC genotype of AT1 gene," adjusted for "maternal age." A multiple logistic model was applied to evaluate the odds ratios of the major risk factors. All statistical analyses were conducted by use of a statistical analysis system package (SAS Institute, Inc., Cary, NC, USA).

\section{Results}

Table 2 shows the distribution of A1166C variants of AT1 determined in 114 patients with severe HP (73 primiparous and 41 multiparous women) and 291 normal controls (165 primiparous and 126 multiparous women). Among the total subjects, the frequencies of allele $\mathrm{C}$ and women with $\mathrm{AC}+\mathrm{CC}$ genotypes were significantly higher in severe HP $(10.1$ and $18.0 \%)$ cases than in controls (5.8 and $10.8 \%$, respectively) (both $p<0.05$ ). Among primiparous subjects, the frequencies were also significantly higher in severe HP (10.3 and $19.2 \%)$ cases than in controls $(4.2$ and $7.9 \%$, respectively) (both $p<0.05$ ), whereas no significant differences were found among multiparous subjects $(9.8$ and $17.1 \%$ in severe HP vs 7.9 and $14.3 \%$ in controls, respectively).

Table 3 shows the odds ratios of selected risk factors before pregnancy for primiparous severe HP. In univariate analyses, four factors, i.e., "AC + $\mathrm{CC}$ genotype of AT1," "TT genotype of AGT," "prepregnancy BMI $\geq 25$," and "family history of hypertension" were significantly associated with primiparous severe HP. Further, multivariate analysis to clarify genotype-genotype confounding with "AC+CC genotype of AT1" and "TT genotype of AGT" revealed that they were independently associated with primiparous severe HP. When "family history of hypertension" and "prepregnancy
BMI $\geq 25$ " were added as examined factors for further multivariate analysis, "TT genotype of AGT" and "family history of hypertension" were found to be independent potent factors. The odds ratios of the two factors were 2.7 and 2.2, respectively, in a multiple logistic model.

\section{Discussion}

The association between $\mathrm{C} 1166$ of the AT1 gene and HP was reported in Caucasian (Nalogowska-Glosnicka et al. 2000) and Polish (Seremak-Mrozikiewicz et al. 2000) subjects. The present study demonstrated not only the association of the AT1 variant with severe HP but also interrelationships among the variants of the AT1 and the AGT genes, high BMI, and family history of hypertension in the manifestation of severe HP in Japanese subjects. The distribution of the AT1 variants in controls observed in this study was compatible with that found in the Japanese population at large (Ono et al. 2003) and displayed Hardy-Weinberg equilibrium.

The category of HP contained two subtypes: women with proteinuric and/or edematous type HP (PE) and women without those features (gestational hypertension; $\mathrm{GH})$. Regarding PE, villous disorders, including abnormal pregnancy-induced spiral artery remodeling occurring early in pregnancy, are thought to be among its causes (Morgan et al. 1999), whereas most GH is believed to be latent essential hypertension unmasked during pregnancy (National High Blood Pressure Education Program Working Group 1990). In the present study, the frequencies of $\mathrm{C} 1166$ and $\mathrm{AC}+\mathrm{CC}$ genotypes

Table 2 Distribution of A1166C variants of $A T 1$ in women with severe hypertension in pregnancy and controls

\begin{tabular}{|c|c|c|c|c|c|c|c|}
\hline \multirow[t]{2}{*}{ Parity } & \multirow[t]{2}{*}{ Diagnosis } & \multirow[t]{2}{*}{ No. of cases studied } & \multicolumn{3}{|c|}{ Genotype } & \multicolumn{2}{|c|}{ Frequency $(\%)$} \\
\hline & & & AA & $\mathrm{AC}$ & $\mathrm{CC}$ & Allele C & $\mathrm{AC}+\mathrm{CC}$ \\
\hline \multirow[t]{2}{*}{ Primipara } & SHP & 73 & 59 & 13 & 1 & $10.3^{*}$ & $19.2^{*}$ \\
\hline & Controls & 165 & 152 & 12 & 1 & 4.2 & 7.9 \\
\hline \multirow[t]{2}{*}{ Multipara } & SHP & 41 & 34 & 6 & 1 & 9.8 & 17.1 \\
\hline & Controls & 126 & 108 & 16 & 2 & 7.9 & 14.3 \\
\hline \multirow[t]{2}{*}{ Total } & SHP & 114 & 93 & 19 & 2 & $10.1^{*}$ & $18.0^{*}$ \\
\hline & Controls & 291 & 260 & 28 & 3 & 5.8 & 10.8 \\
\hline
\end{tabular}

SHP, severe hypertension in pregnancy

$* p<0.05$ vs controls tested by chi-square test $(\mathrm{df}=1)$

Table 3 Odds ratios of selected risk factors existing before pregnancy for primiparous severe hypertension in pregnancy: multivariate analysis

\begin{tabular}{llll}
\hline & Crude OR $(95 \% \mathrm{CI})$ & OR $(95 \% \mathrm{CI})^{\mathrm{a}}$ & OR $(95 \% \mathrm{CI})^{\mathrm{b}}$ \\
\hline AC + CC genotype of $A T 1$ & $2.8(1.2-6.3)^{*}$ & $2.4(1.0-5.7)^{*}$ & $2.3(1.0-5.6)$ \\
TT genotype of $A G T$ & $2.6(1.4-4.8)^{* *}$ & $2.7(1.4-5.1)^{* *}$ & $2.7(1.4-5.4)^{* *}$ \\
Prepregnancy BMI $\geq 25$ & $2.5(1.0-6.1)^{*}$ & - & $2.6(1.0-6.7)$ \\
Family history of hypertension & $2.6(1.3-4.9)^{* *}$ & - & $2.2(1.1-4.5)^{*}$ \\
\hline
\end{tabular}

$* p<0.05, * * p<0.01, * * * p<0.001$

${ }^{a}$ Multivariate analysis with $\mathrm{AC}+\mathrm{CC}$ genotype of $A T 1$ and $\mathrm{TT}$ genotype of $A G T$, adjusted for maternal age

${ }^{\mathrm{b}}$ Multivariate analysis with $\mathrm{AC}+\mathrm{CC}$ genotype of $A T 1$, TT genotype of $A G T$, prepregnancy BMI $\geq 25$ and family history of hypertension, adjusted for maternal age 
were 19.6 and $34.7 \%(8 / 23)$, respectively, in severe GH and 7.7 and $14.2 \%(13 / 91)$, respectively, in severe PE (the data are not shown in the tables). Our results seem to be consistent with the previous reports that demonstrated an association between C1166 of the AT1 gene and essential hypertension (Bonnardeaux et al. 1994; Szombathy et al. 1998; Jiang et al. 2001), although the number of the cases are small yet. We think it is necessary in future studies to clarify whether C1166 is particularly associated with severe GH or not and whether $\mathrm{C} 1166$ is associated with cases that have both $\mathrm{GH}$ and latent essential hypertension.

In the final multivariate analysis, the factors "family history of hypertension" and "prepregnancy BMI $\geq 25$ " reduced the $p$-values of "AC $+C C$ genotype of AT1," and eliminated the significance, suggesting that these factors were not independent of each other, whereas, "TT genotype of AGT" was found to be independent of these factors. This result was consistent with the previously proposed hypothesis that the T235 variant of the AGT gene may be concerned with abnormal pregnancy-induced spiral artery remodeling (Morgan et al. 1999). On the other hand, the AC(CC) genotypes of AT1 may be related to the family history of hypertension and prepregnancy high BMI, which were concerned with the predisposition to essential hypertension.

The molecular and biochemical mechanism by which the A1166C variant of the AT1 gene is involved in the manifestation of HP is still obscure, since the variable nucleotide is located in the $3^{\prime}$ untranslated region (Duncan et al. 2001). The allele $\mathrm{C} 1166$ has been reported to be associated with aortic stiffness (Lajemi et al. 2001) but not associated with hypertension in the elderly (Liyou et al. 1999). In the present study, no significant association was found between AT1 and HP in elderly pregnancy, and multivariate analysis also revealed that the association of AT1 with HP was independent of maternal age. It was reported that the A1166C polymorphism does not have a major effect on the actions of angiotensin II (Hilgers et al. 1999), while the polymorphism was found to be associated with salt sensitivity in hypertensive patients (Spiering et al. 2000). Elucidation of whether there is synergism and/or interaction between the AT1 genotype and dietary salt intake during pregnancy in the manifestation of HP will be the next goal of our future studies.

In summary, C1166 of the AT1 gene was associated with severe HP independently of T235 of the AGT gene in Japanese subjects. Further studies enrolling larger population samples and different ethnic groups will be useful for elucidating the pathogenesis of HP and establishing preventive strategies against HP.

Acknowledgements Cordial thanks are due to the many collaborators who supplied cases and controls in the Department of Obstetrics and Gynecology of Hokkaido University Hospital and its affiliated hospitals. We would also like to express our gratitude to Dr. H. Tamashiro for advice, Ms. M. Funamizu for technical assistance and Dr. E. Nakajima for critical assistance in manuscript preparation. This work was supported in part by a grant-in-aid from the Japanese Ministry of Education, Science and Culture, a grant from the Hokkaido Foundation for the Promotion of Scientific Industrial Technology, and the 16th Research Grant of the Nakatomi Foundation.

\section{References}

Bonnardeaux A, Davies E, Jeunemaitre X, Fery I, Charru A, Clauser E, Tiret L, Cambien F, Corvol P, Soubrier F (1994) Angiotensin II type 1 receptor gene polymorphisms in human essential hypertension. Hypertension 24:63-69

Caulfield M, Lavender P, Farrall M, Munroe P, Lawson M, Turner P, Clark AJ (1994) Linkage of the angiotensinogen gene to essential hypertension. N Engl J Med 330:1629-1633

Duncan JA, Scholey JW, Miller JA (2001) Angiotensin II type 1 receptor gene polymorphisms in humans: physiology and pathophysiology of the genotypes. Curr Opin Nephrol Hypertens 10:111-116

Hata A, Namikawa C, Sasaki M, Sato K, Nakamura T, Tamura K, Lalouel JM (1994) Angiotensinogen as a risk factor for essential hypertension in Japan. J Clin Invest 93:1285-1287

Hilgers KF, Langenfeld MR, Schlaich M, Veelken R, Schmieder RE (1999) $1166 \mathrm{~A} / \mathrm{C}$ polymorphism of the angiotensin II type 1 receptor gene and the response to short-term infusion of angiotensin II. Circulation 100:1394-1399

Inoue I, Nakajima T, Williams CS, Quackenbush J, Puryear R, Powers M, Cheng T, Ludwig EH, Sharma AM, Hata A, Lalouel J-M (1997) A nucleotide substitution in the promoter of human angiotensinogen is associated with essential hypertension and affects basal transcription in vitro. J Clin Invest 99:1786-1797

Jeunemaitre X, Soubrier F, Kotelevtsev YV, Lifton RP, Williams CS, Charru A, Hunt SC, Hopkins PN, Williams RR, Lalouel JM, Corvol P (1992) Molecular basis of human hypertension: role of angiotensinogen. Cell 71:169-180

Jiang Z, Zhao W, Yu F, Xu G (2001) Association of angiotensin II type 1 receptor gene polymorphism with essential hypertension. Chin Med J (Engl) 114:1249-1251

Kobashi G, Hata A, Shido K, Kato EH, Yamada H, Fujimoto S, Kishi R, Kondo K (1999) Association of a variant of the angiotensinogen gene with pure type of hypertension in pregnancy in the Japanese: implication of a racial difference and significance of an age factor. Am J Med Genet 86:232-236

Lajemi M, Labat C, Gautier S, Lacolley P, Safar M, Asmar R, Cambien F, Benetos A (2001) Angiotensin II type 1 receptor$153 \mathrm{~A} / \mathrm{G}$ and $1166 \mathrm{~A} / \mathrm{C}$ gene polymorphisms and increase in aortic stiffness with age in hypertensive subjects. J Hypertens 19:407-413

Liyou N, Davis D, James K, Simons L, Friedlander Y, Simons J, McCallum J, Johnson A (1999) The A1166C mutation in the angiotensin II type I receptor and hypertension in the elderly. Clin Exp Pharmacol Physiol 26:525-526

Morgan T, Craven C, Lalouel JM, Ward K (1999) Angiotensinogen Thr235 variant is associated with abnormal physiologic change of the uterine spinal arteries in first-trimester decidua. Am J Obstet Gynecol 180:95-102

Nalogowska-Glosnicka K, Lacka BI, Zychma MJ, Grzeszczak W, Zukowska-Szczechowska E, Poreba R, Michalski B, Kniazewski B, Rzempoluch J, PIH Study Group (2000) Angiotensin II type 1 receptor gene A1166C polymorphism is associated with the increased risk of pregnancy-induced hypertension. Med Sci Monit 6:523-529

National High Blood Pressure Education Program Working Group (1990) Report on high blood pressure in pregnancy (Consensus Report). Am J Obstet Gynecol 163:1689-1712

Ono K, Mannami T, Baba S, Yasui N, Ogihara T, Iwai N (2003) Lack of association between angiotensin II type 1 receptor gene polymorphism and hypertension in Japanese. Hypertens Res 26:131-134 
Russ AP, Maerz W, Ruzicka V, Stein U, Gross W (1993) Rapid detection of the hypertension-associated Met235 $\rightarrow$ Thr allele of the human angiotensinogen gene. Hum Mol Genet 2:609-610

Schmidt S, Beige J, Walla-Friedel M, Michel MC, Sharma AM, Ritz E (1997) A polymorphism in the gene for the angiotensin II type 1 receptor is not associated with hypertension. J Hypertens 15:1385-1388

Seremak-Mrozikiewicz A, Drews K, Chmara E, Mrozikiewicz PM, Slomko Z (2000) Gestational hypertension $(\mathrm{GH})$ and a1166c polymorphism of angiotensin II type 1 receptor. Ginekol Pol 71:783-788

Spiering W, Kroon AA, Fuss-Lejeune MM, Daemen MJ, de Leeuw PW (2000) Angiotensin II sensitivity is associated with the angiotensin II type 1 receptor $\mathrm{A}(1166) \mathrm{C}$ polymorphism in essential hypertensives on a high sodium diet. Hypertension $36: 411-416$

Szombathy T, Szalai C, Katalin B, Palicz T, Romics L, Csaszar A (1998) Association of angiotensin II type 1 receptor polymor- phism with resistant essential hypertension. Clin Chim Acta 269:91-100

Takami S, Katsuya T, Rakugi H, Sato N, Nakata Y, Kamitani A, Miki T, Higaki J, Ogihara T (1998) Angiotensin II type 1 receptor gene polymorphism is associated with increase of left ventricular mass but not with hypertension. Am J Hypertens $11: 316-321$

Tamakoshi A, Ishikawa S, Ojima T, Kikuchi S, Kobashi G, Saito Y, Sugimori H, Nakamura Y, Nakayama T, Muto K, Yamagata Z, Washio M (2000) The guideline of informed consent in epidemiological studies, ver. 1.0. Nihonijishinposya, Tokyo, pp 1-27

Ward K, Hata A, Jeunemaitre X, Helin C, Nelson L, Namikawa C, Farrington PF, Ogasawara M, Suzumori K, Tomoda S, Berrebi S, Sasaki M, Corvol P, Lifton RP, Lalouel JM (1993) A molecular variant of angiotensinogen associated with preeclampsia. Nat Genet 4:59-61 